F. Buxant · M.H. Ansion · J.C. Noël

V. Anaf · P. Simon

\title{
Laparoscopic management of a cornual ectopic pregnancy
}

Received: 22 October 2004 / Accepted: 17 February 2005/Published online: 21 May 2005

(C) Springer-Verlag Berlin / Heidelberg 2005

\begin{abstract}
There are various possibilities for treating cornual ectopic pregnancies, including medical approaches using methotrexate and surgical approaches using laparoscopy. This report describes the laparoscopic management of a large cornual ectopic pregnancy associated with a high $\beta$-human chorionic gonadotropin level and reviews the techniques and outcomes of conservative treatment described in the literature.
\end{abstract}

Keywords Cornual ectopic pregnancy $\cdot$ Laparoscopy

\section{Introduction}

Cornual implantation of an ectopic pregnancy is a rare event. It represents $2-4 \%$ of all tubal pregnancies but has an estimated maternal mortality of $2-2.5 \%$ because of the risk of cornual rupture [11].

By definition, a cornual pregnancy develops in the fallopian tube's proximal myometrial portion, which is $0.7 \mathrm{~mm}$ wide and $1-2 \mathrm{~cm}$ long with a slightly tortuous course, extending obliquely upward and outward from the uterine cavity. A pregnancy implanted in this site is also called an interstitial pregnancy. Predisposing factors to cornual pregnancy include previous ectopic pregnancy, a history of ipsilateral salpingectomy, and in vitro fertilization. Diagnosis is generally based on the $\beta$ human chorionic gonadotropin (hCG) level and on transvaginal ultrasound.

F. Buxant · M. Ansion · J. Noël · V. Anaf · P. Simon

Department of Obstetrics \& Gynaecology, CUB Hospital Erasme, Free University of Brussels, 1070 Brussels, Belgium

F. Buxant $(\bowtie)$

Department of Pathology, CUB Hospital Erasme, Free University of Brussels, 1070 Brussels, Belgium

E-mail: frederic.buxant@ulb.ac.be

Tel.: + 32-2-5553684

Fax: + 32-2-5556841
Traditional treatment of cornual pregnancy consists of hysterectomy or cornual resection by laparotomy. It is only recently that cornual pregnancies have been treated in a conservative way, by laparoscopy or by local or systemic administration of methotrexate (MTX). Laparoscopic treatments include cornual resection, cornuostomy, salpingostomy, or salpingectomy [11]. Hysteroscopic treatments have also been described $[3,8]$.

\section{Case report}

A 26-year-old African woman, gravida 5, para 2, with no complaints and with an estimated gestational age of 6.5-7 weeks according to the last menstrual period, presented to her gynaecologist. She had a history of right tubal ectopic pregnancy 3 years previously, which had been treated by salpingostomy, and a miscarriage that could not be dated. She had also had an appendectomy. There were no other medical or surgical antecedents. Clinical and vaginal examinations were normal.

Her $\beta$-hCG level had been $88,650 \mathrm{mIU} / \mathrm{ml} 4$ days earlier. Transvaginal ultrasound (Fig. 1) revealed an empty uterus with an endometrial thickness of $14 \mathrm{~mm}$. There was a right parauterine mass, $45 \times 36 \mathrm{~mm}, 3 \mathrm{~mm}$ from the uterine cavity near the right uterine cornua, and no free fluid in the pouch of Douglas. The ovaries were normal.

Preoperative examinations were carried out with a new $\beta$-hCG level, which was 109,097 $\mathrm{mIU} / \mathrm{ml}$.

A diagnostic laparoscopy was performed the following day to exclude a cornual ectopic pregnancy. At the laparoscopy, we found a $5-\mathrm{cm}$ mass in the right uterine cornua (Fig. 2). The other pelvic organs were without particularity. A 5-mm port was placed in the left lower quadrant, and a $10-\mathrm{mm}$ one was placed in the right lower quadrant. A transparietal injection of $2 \%$ Xylocaine-adrenaline solution was made into the right cornual area, around the pregnancy (Fig. 3). 


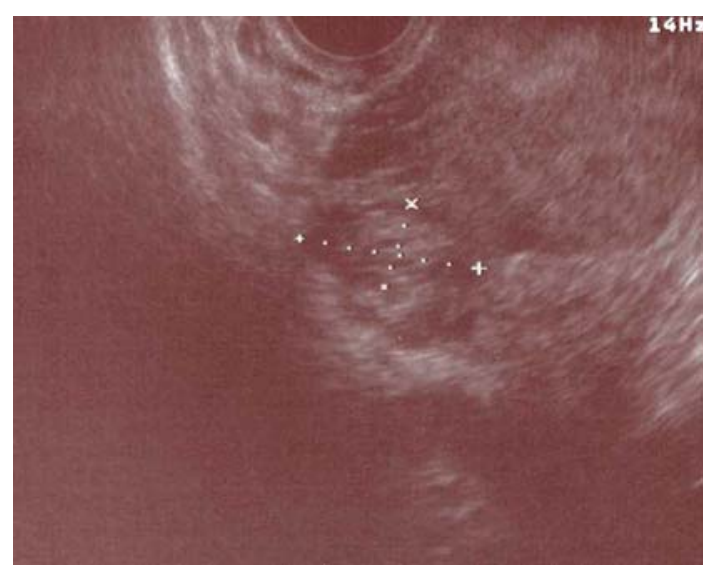

Fig. 1 Transvaginal ultrasound: a right parauterine mass with an empty uterine cavity

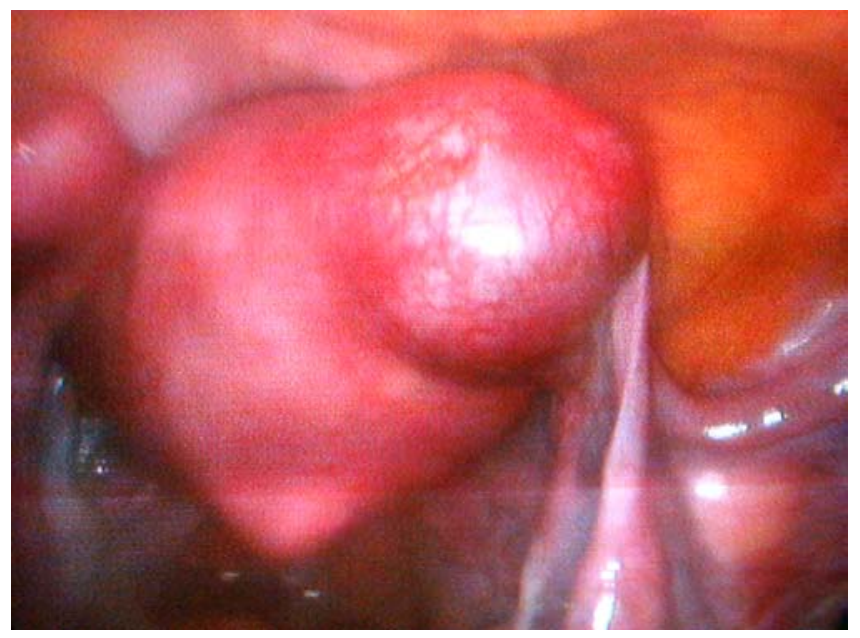

Fig. 2 Right cornual pregnancy

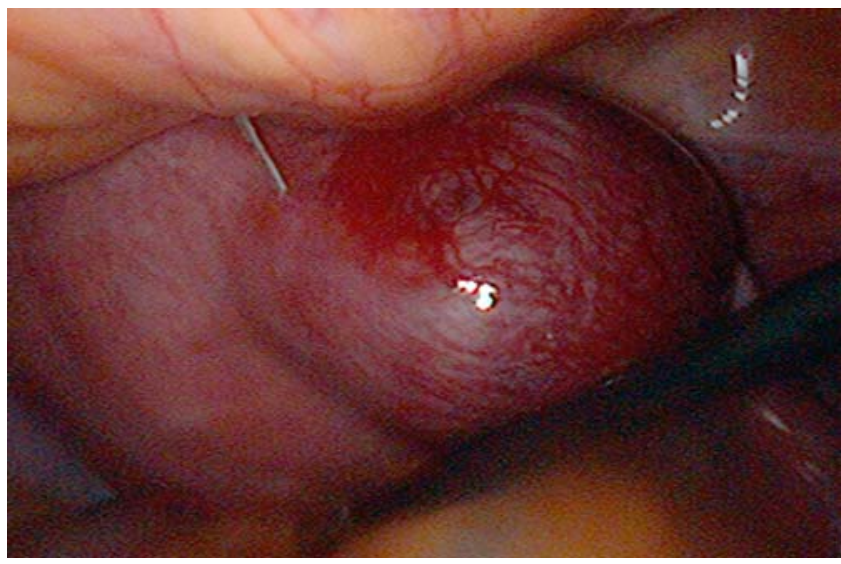

Fig. 3 Transparietal injection of Xylocaine-adrenaline

Then an incision was made in the right cornua using monopolar scissors, and we expressed the gestation through the incision (Fig. 4). The uterine incision was closed using Vicryl 1 (Fig. 5).

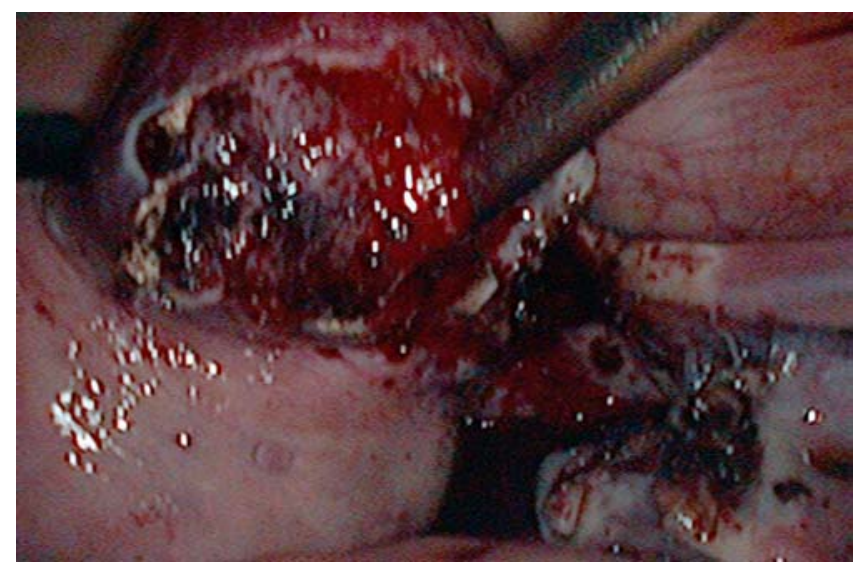

Fig. 4 Incision in the right uterine cornua and drainage of trophoblastic material

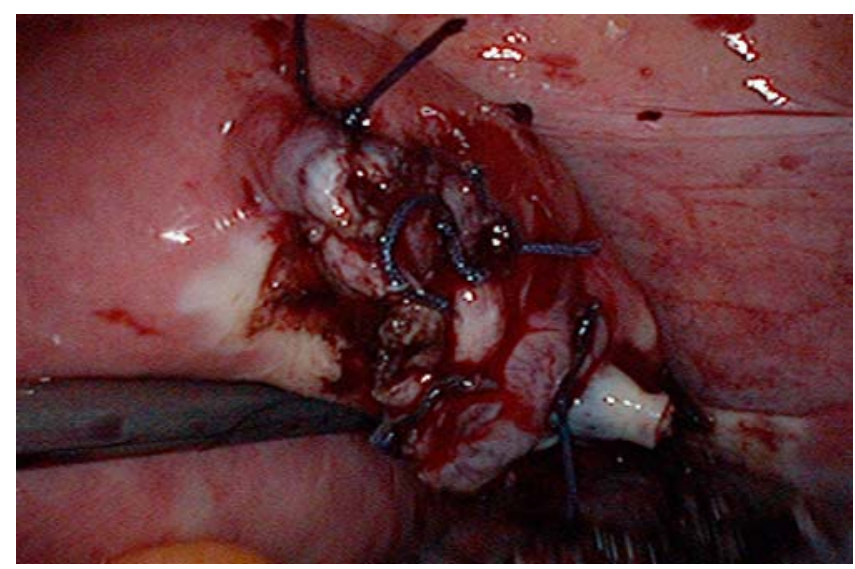

Fig. 5 Incision sutured with Vicryl 1

The histology report confirmed the presence of an evolutionary pregnancy younger than 12 weeks.

In the postoperative period, treatment was completed by an intramuscular injection of MTX $(1 \mathrm{mg} / \mathrm{kg})$. The patient had no postoperative complications. A $\beta$-hCG level was done three days later and was $6,848 \mathrm{mIU} / \mathrm{ml}$. The patient returned home on the 5th day and was seen 10 days after the intervention for a new $\beta$-hCG level and a clinical and vaginal examination. She complained of some spotting, but the physical examination was absolutely normal and the $\beta$-hCG level was $107 \mathrm{mIU} / \mathrm{ml}$. A transvaginal ultrasound was performed and showed a post-right salpingectomy status and normal pelvic organs remaining.

\section{Discussion}

Because of the low incidence of cornual ectopic pregnancy, the findings in the literature are mostly case reports. A history of previous ectopic pregnancy, ipsilateral salpingectomy, or/and in vitro fertilization is often present. This confirms that salpingectomy does not 
prevent the development of ectopic pregnancy in the interstitial part of the ipsilateral tube [11].

Early diagnosis is important for management. Clinical examination, the $\beta$-hCG level, and transvaginal ultrasound constitute the principal diagnostic tools.

The $\beta$-hCG level is generally higher than in tubal ectopic pregnancy. This could be explained by the better quality of the interactions between the conceptus and its implantation bed, thus improving the kinetics of hCG [6]. Most $\beta$-hCG levels found in the literature are often lower than $10,000 \mathrm{mIU} / \mathrm{ml}$; in our patient, levels were higher. Because it is recommended to limit medical treatment to pregnancies with weak $\beta$-hCG levels because of the link to the viability of the conceptus [4], we decided to direct ourselves to surgical management as first intention.

Sonographic criteria have been described in the ultrasonographic diagnosis of cornual ectopic pregnancies: (1) an empty uterine cavity, (2) a chorionic sac seen separately, and (3) a thin myometrial layer surrounding the chorionic sac. With these parameters, a specificity of $88-93 \%$ and a sensitivity of $40 \%$ can be reached.

Others have described an "interstitial line sign," which is the visualization of an echogenic line extending into the cornual region and abutting the midportion of the interstitial mass or gestational sac. For this sign, the sensitivity is $80 \%$ and the specificity is $98 \%$ [7].

Recently, Tulandi and Al-Jaroudi [11] showed that ultrasound revealed a gestational sac in $40.6 \%$ of cases and a hyperechoic mass in the cornual area in another $25 \%$.

This was the case in our patient, only a right parauterine mass near the right cornua area was seen. Laparoscopy was decided upon with the patient, while we explained the possibility of a therapeutic act at the same time.

There are several types of conservative treatment for a cornual ectopic pregnancy. The respective success rates for medical and surgical treatment, as reported by Canis et al. [4], are $65-95 \%$ and $72-95 \%$.

The laparoscopic technique is the most common surgical treatment due to the quickness of the diagnosis. Various operative laparoscopic techniques are described; the most frequently used is incision of the cornual area after vasopressin injection, drainage of the trophoblastic material through the incision, and hysterotomy suture $[5-7,9,12]$. Other laparoscopic methods use fibrin glue haemostasis [9], use the endoloop before evacuating the conceptus $[3,10]$, or encircle the suture before evacuating the conceptus [3].

Hysteroscopic management for cornual ectopic pregnancy has also been reported $[3,7,8]$.

Hysterectomy and subtotal hysterectomy can be proposed to women who do not desire more children. These techniques offer the advantage of needing no medical treatment after the surgery.

There are also different medical treatments: systemic or local injections of MTX $[1,4,6,7,11]$ or local injections of potassium chloride $[1,2,4,6]$ or prostaglandin
$\left(\mathrm{PGF}_{2 \alpha}\right)$ [1], with all of these given under ultrasound, laparoscopic, or hysteroscopic guidance. Agents other than MTX are also used: systemic RU486 [1], actinomycin D [6], or etoposide under echographic control $[4,6]$.

Treatment with systemic MTX is not always successful, and rupture may occur during treatment. Local injection techniques are not without risks, and haemorrhage or even cornual rupture can occur [3].

In the follow-up of a later intrauterine pregnancy in a patient who was treated for cornual ectopic pregnancy, a term caesarean must be considered before labour begins because of the risk of rupture of a cicatricial uterus [6].

Criteria for choosing between surgical and medical treatment are not precise as yet.

In our case we used the "classical" laparoscopic method, except we automatically used a systemic injection of MTX $(1 \mathrm{mg} / \mathrm{kg})$ after surgery. This decision was made because of the patient's high $\beta$-hCG levels and the uncertainty of complete resection of the gestation (accessibility of the implantation area). The patient responded well to treatment, and her $\beta$-hCG level was $107 \mathrm{mIU} / \mathrm{ml} 10$ days after surgery.

\section{Conclusion}

A high $\beta$-hCG level does not prevent successful laparoscopic management of a cornual pregnancy. Unfortunately, we have little knowledge of the evolution and follow-up of subsequent pregnancies.

\section{References}

1. Batioglu S, Haberal A, Yesilyurt H, Ekici E (1997) Successful treatment of cornual pregnancy by local injection of methotrexate under laparoscopic and transvaginal ultrasonographic guidance. Gynecol Obstet Invest 44(1):64-66

2. Benifla JL, Fernandez H, Sebban E, Darai E, Frydman R, Madelnat P (1996) Alternative to surgery of treatment of unruptured interstitial pregnancy: 15 cases of medical treatment. Eur J Obstet Gynecol Reprod Biol 70(2):151-156

3. Pal B, Akinfenwa O, Harrington K (2003) Hysteroscopic management of cornual ectopic pregnancy. BJOG 110:879880

4. Canis M, Savary D, Pouly JL, Wattiez A, Mage G (2003) Ectopic pregnancy: criteria to decide between medical and surgical treatment? J Gynecol Obstet Biol Reprod (Paris) 32(7 suppl):S54-S63 (French)

5. Grobman WA, Milad MP (1998) Conservative laparoscopic management of a large cornual ectopic pregnancy. Hum Reprod 13(7):2002-2004

6. Jourdain O, Fontanges M, Schiano A, Rauch F, Gonnet JM (2003) Management of other ectopic pregnancies (cornual, interstitial, angular, ovarian). J Gynecol Obstet Biol Reprod (Paris) 32(7 suppl):S93-S100 (French)

7. Lau S, Tulandi T (1999) Conservative medical and surgical management of interstitial ectopic pregnancy. Fertil Steril 72(2):207-215

8. Minelli L, Landi S, Giamberto T, Fiaccavento A, Barbieri F (2003) Cornual pregnancy successfully treated by suction curettage and operative hysteroscopy. BJOG 110:1132-1134 
9. Morita Y, Tsutsumi O, Momoeda M, Taketani Y (1997) Cornual pregnancy successfully treated laparoscopically with fibrin glue hemostasis. Obstet Gynecol 90(4 Pt 2):685-687

10. Sergent F, Le Cornec JB, Meilhaud MF, Marpeau L (2003) Laparoscopic cornual excision with an automatic stapler for ruptured interstitial pregnancies. J Gynecol Obstet Biol Reprod (Paris) 32(5):426-430 (French)
11. Tulandi T, Al-Jaroudi D (2004) Interstitial pregnancy: results generated from the society of reproductive surgeons registry. Obstet Gynecol 103(1):47-50

12. Vicino M, Loverro G, Resta L, Bettocchi S, Vimercati A, Selvaggi L (2000) Laparoscopic cornual excision in a viable large interstitial pregnancy without blood flow detected by color Doppler ultrasonography. Fertil Steril 74(2):407-409 